\title{
Free Indirect Thought in Stream-of-Consciousness Fiction: A Textural Cohesive Perspective
}

\author{
Hua Guo ${ }^{1}$ \\ ${ }^{1}$ College of Foreign Languages and Literatures, Fudan University, Shanghai, China \\ Correspondence: Hua Guo, College of Foreign Languages and Literatures, Fudan University, Shanghai, China. \\ E-mail: guohua@fudan.edu.cn
}

Received: July 27, 2017 Accepted: August 29, 2017 Online Published: September 15, 2017

doi:10.5539/ijel.v7n6p38 URL: http://doi.org/10.5539/ijel.v7n6p38

\begin{abstract}
Free indirect thought (FIT) is an important linguistic device to portray characters in stream-of-consciousness fiction. Most studies are concerned with its linguistic manifestations that align the text with the character's point of view, and not much attention is given to the implicit coherence underlying FIT's seemingly disconnected and disorganized structures. Using cohesion theory (Halliday \& Hasan, 1985), this article analyzes FIT extracts of the two major characters in Mrs. Dalloway. The analysis is conducted to examine the non-structural cohesive devices and the cohesive chains these devices form and explore their unique contribution to the depiction of characters' thought processes and distinctive personalities.
\end{abstract}

Keywords: stream of consciousness, free indirect thought, cohesion, Mrs. Dalloway

\section{Introduction}

The beginning of the $20^{\text {th }}$ century has witnessed a change in the way writers create characters, which culminates in the stream-of-consciousness technique that aims to present rather than describe various aspects of human personality and of the working of the mind (Balossi, 2014). Deeply influenced by intellectual trends like Freud's psychoanalysis, stream-of-consciousness writers believe that the truth of reality resides not in the facts of the outside world but in man's mental experience and subjective construction of the external facts, which underlies their experiments with narrative form. For example, Woolf (2002 [1925]) claims to "record the atoms (i.e. the myriad impressions) in the order in which they fall upon the mind" (p. 61), and opts out of the "formal railway line of sentence" (Lee, 2010 [1977], p. 93) and for "the fragmented structure of the flight of the mind" (Dick, 2001, p. 51), where she imitates "the selective process by which we know and recollect ourselves, one another, and our world" (ibid.). In addition to a literary form, stream of consciousness is also considered a type of content that is "characterized by free association, the illusion of spontaneity, and constant micro-shifts among perception, introspection, anticipation, speculation, and memory" (McHale, 2009, pp. 434-446).

Compared with the plot-based fiction, stream-of-consciousness fiction, with its central concern with man's inner reality, has its particularity in terms of theme, structure and language. Readers often feel that they can only capture the character's "random ordering of thoughts and impressions" that do not emerge "to some purpose" (Chatman, 1978, p. 188), and fail to understand the character's mental states and their personality traits. This is largely due to the author's extensive use of a particular category of thought presentation, free indirect thought (FIT), which is often associated with "dual voice" (Pascal, 1977), seemingly conflating the character's text and the narrator's text. On the one hand, this linguistic device "makes the character's thoughts more naturally blended with narration," (Shen, 1991, p. 14) which is conducive to the non-intrusive representation of the character's changing states of mind under the influence of external events and factors, and in the meantime it is "apt for the representation of sense impressions that characters could feel but could not articulate" (ibid.). On the other hand, it makes the text less ordered and organized, impedes the reader's efforts to establish textual coherence, and thus imposes extremely high demands on the reader's "mind-reading ability" (Zunshine, 2003, p. 278).

To resolve this mind reading difficulty, this article uses cohesion theory (Halliday \& Hasan, 1985) to explore the unity and coherence underneath the apparent fragmentation and disconnection of FIT presentations in Mrs. Dalloway, a masterpiece of Woolf's stream-of-consciousness creation, and find out in what way cohesion participates in and contributes to the portrayal of characters and theme building. Cohesion "refers to relations of 
meaning that exist within the text, and that define it as text" (Halliday \& Hasan, 1976, p. 4), and cohesion theory is an effective means to explicate semantic relations and textual coherence. For the present study, whereas stream of consciousness writers manipulate linguistic resources to present the intangible reality in human mind as contrasts with the actuality of the observable world, cohesion theory also acknowledges the importance of men's cognition and interpretation in identifying cohesive ties with co-text and context clues. Further, non-intrusively as stream-of-consciousness writers purport to represent character's subjectivity in constant switches of perspectives, which poses formidable obstacles for readers more accustomed to fiction with a linear structure and a clear plot, cohesive devices help to trace out the linguistic hints the writer drops for mental representation. Cohesion theory can therefore be of avail to thread these hints and help bridge the gap between the writer's production and the reader's comprehension in the case of stream-of-consciousness fiction.

\section{Literature Review}

Discourse presentation, in particular, free indirect discourse in Virginia Woolf's stream-of-consciousness fiction has attracted considerable interest from linguists and literary critics (Banfield, 1982; Cui, 2014; Ehrlich, 1990; Ikeo, 2015; Lambert, 2011; Sotirova, 2004, 2007, 2013). Quite a few studies do not distinguish free indirect thought from free indirect speech, and use free indirect speech (sometimes free indirect style) as a generic term, under which FIT is in effect a subcategory (e.g., Fludernik,1993; Sotirova, 2004). Hernadi (1972) might be the first to draw a distinction between speech and thought, and contends that mental activities in characters' minds comprise "quasi-verbal" (p. 39) contents of the imaginative worlds literary works evoke. That is to say, whereas speech and perception constitute verbal and nonverbal components of the worlds, the presentation of thought, be it conscious or not, indicates the presence of operations similar to but not the same as verbal communication in human mind. Leech \& Short $(1981,2007)$ further point out that thought is generally not accessible to others and might not be formulated linguistically in the same way as speech. Hence thought cannot be described verbatim, and "the representation of the thoughts of characters, even in an extremely indirect form, i.e., narrative report of thought acts, is ultimately an artifice" (p. 337). However, FIT is the second most frequent category of thought presentation in Semino \& Short's (2004) SW\&TP corpus, and in stream-of- consciousness fiction like Mrs. Dalloway, thought presentation is essentially important in that the fiction is mostly comprised of characters' reflections, impressions and emotions, and thought presentation in its various forms mimics the possible process as the character actually experiences these particular moments of their mental activities, thus further contributing to clarifying the motivation behind characters' speech, action, and attitude.

Free indirect discourse is generally considered a mode of discourse presentation which blends "deictic and modal features of two projected discourse, the narrator's and the character's" (Sotirova, 2004, p. 216). FIT, in particular, mixes the narrator's text with the character's and appeals to writers as it "provides a singularly adequate mode of evoking whatever goes on in a character's mind" (Hernadi, 1972, p. 39) and is flexible "in terms of formal features and its usefulness in presenting thoughts in a dramatic and immediate way, but without the more obvious artificiality of (F)DT" (Semino \& Short, 2004, p. 123). Apart from linguistic features that help establish this mode of thought presentation (e.g., Fludernik, 1993; McHale, 1978; Pascal, 1977; Toolan, 2008 [1996]), researchers are concerned with features that do not exactly fit into the established standards but still indicate the character's viewpoint. For example, Cui (2014) argues for parentheticals facilitating "multipersonal representation of consciousness", which is initially discussed by Auerbach (2003 [1953], p. 536). In addition to the linguistic features that tinge the narrator's text with the character's viewpoint, the existing studies also discuss the narrative functions of this particular mode of thought presentation which range from "empathetic identification" to "ironic repudiation" (McHale, 2009, pp. 434-446). These studies play a significant role in identifying individual examples of FIT and recognizing their effects in narrative contexts, but it seems that they fail to give adequate attention to the linguistic features and effects of FIT on the textual level and do not contribute much to the interpretation of characters' thought which is apparently illogical and disorganized. For instance,

The world wavered and quivered and threatened to burst into flames. It is I who am blocking the way, he thought.

These two sentences describe the thoughts of Septimus, a major character in Mrs. Dalloway. The first sentence depicts his hallucinations on hearing a car backfire and his fear of the shaky world. The second sentence with its emphatic structure presents his speculation that he is responsible for the traffic jam. These two sentences appear disconnected at first glance, and it is only with the inspection of cohesive devices and the interpretation of Septimus's comparing himself to a tree that some coherence might be established as shown in 4.2.

Cohesion theory is an effective means to explain semantic ties and textual coherence. According to Halliday \& 
Hasan (1985), cohesive tie is most essential to texture, which is a source of textual unity and is "manifested by certain kinds of semantic relations between its individual messages" (p. 71). The kinds of meaning relations that can obtain between the two members of a cohesive tie are classified into co-referentiality (identity of reference), co-classification (identity of class) and co-extension (identity of general field of meaning). As these sense relations are normally realized by a definable set of lexico-grammatical patterns, they divide these cohesive devices (i.e. non-structural devices as contrast with structural devices, which are essential to the structure of a text, another source of textual unity) into componential relations and organic relations. Componential relations are realized through the use of reference, substitution and ellipsis, and lexical cohesion. Organic relations are established through conjunctives and adjacency pairs in the grammatical category and continuatives in the lexical category (pp. 72-86). These non-structural devices are illustrated in Table 1. Moreover, in addition to cohesive chains that form on the basis of relations of identity or similarity between lexical cohesive devices, chain interaction is present to explain the grammatical relations between members of two or more distinct chains. These important notions can be applied to expound cohesive features of FIT excerpts within the text and between text and situation, and facilitate the interpretation of the character's thinking habits and dispositions.

Table 1. Non-structural cohesion

\begin{tabular}{|c|c|c|c|}
\hline \multirow{2}{*}{$\begin{array}{l}\text { Componential relations } \\
\text { Reference }\end{array}$} & \multicolumn{3}{|c|}{ Organic relations } \\
\hline & \multicolumn{2}{|c|}{ Grammatical cohesive devices } & \multirow[b]{2}{*}{ e.g., Causal ties } \\
\hline Reference & $\begin{array}{l}\text { e.g., it (pronominal) } \\
\text { this, that (demonstrative) } \\
\text { the (definitive article) }\end{array}$ & Conjunctives & \\
\hline Substitution\& Ellipsis & $\begin{array}{l}\text { e.g., I play the cello. My husband } \\
\text { does, too. } \\
\text { (substitution) } \\
\text { Can I borrow your pen? Yes, but } \\
\text { what happened to yours? (ellipsis) }\end{array}$ & Adjacency pairs & $\begin{array}{l}\text { e.g., Question (followed by) } \\
\text { answer }\end{array}$ \\
\hline \multicolumn{4}{|c|}{ Lexical cohesive devices } \\
\hline \multicolumn{2}{|c|}{$\begin{array}{l}\text { e.g., smile and grin (synonym), man and woman (antonym), animal } \\
\text { and cat (hyponymy), tree and root (meronymy), there are children } \\
\text { on the swings, and children on the merry-go-round (repetition) }\end{array}$} & Continuatives & e.g., still \\
\hline \multicolumn{4}{|c|}{ Adapted from "Non-structural cohesion" by Halliday \& Hasan $(1985$, p. 82$)$} \\
\hline
\end{tabular}

\section{Methods}

In stylistics, thought presentation is usually studied along a continuum depending on whether the narrator or the character is speaking or both are speaking and linguistic features are considered in individuating thought presentation categories (e.g., McHale, 1978; Leech \& Short, 1981, 2007; Semino \& Short, 2004; Toolan, 2008 [1996]). Recent research in cognitive poetics (e.g., Gavins \& Steen, 2003; Herman, 2011; Palmer, 2004; Zunshine, 2003) has downplayed the category approach to thought presentation, and instead prefers a "cognitive science-based methodology that is less grounded in linguistic analysis" (Rundquist, 2014, p. 159). The present study adopts the category approach on the grounds that differentiated categories "have different semantic effects in terms of the extent to which they express verbal or non-verbal mental activity, as well as the aspects of consciousness that they evoke" (ibid.). Leech \& Short's model $(1981,2007)$, one of the most influential models typical of the category approach, is concerned with the narrator's control over the character's perspective, and is well accepted for its wide and systematic coverage of thought presentation categories. As Simpson (1993) notes, it remains "the most accessible introduction to the topic" and "Leech and Short base their categories on explicit linguistic criteria and offer numerous examples from prose fiction in support of their framework" (p. 21). This explicitness which Simpson mentions ensures the reliability in applying this model to actual stylistic analysis of thought presentation cases.

FIT is defined according to Leech \& Short (2007) as a mode of thought presentation between direct thought (DT) and indirect thought (IT). FIT typically differs from DT "by virtue of the back-shift of the tense and the conversion of the first-person pronoun to the third person (indirect features) and also by the absence of a reporting clause and the retention of the interrogative form and question mark (direct features) (p. 271). This definition, however, is likely to place IT with reporting clauses and free features associated with DT in a suspicious status. Besides, as their functional and pragmatic criteria inevitably involve readers' reception and interpretation of the textual material, uncertainty and ambiguity is expected in deciding on possible FIT 
presentations. For the sake of analysis, a set of features are proposed to help single out FIT. The feature associated with IT is (1) tense (Leech\& Short, 2007), as once the tense is transferred from a DT instance, the thought category is almost without exception a(n) (F)DS instance. Features associated with DT are (2) retention of interrogative mood and question mark if any (Leech \& Short, 2007), (3) syntactic independence(e.g., She did not much like parties, Elizabeth said, Fludernik, 1993) (4) deictic expressions (e.g., me, here, now, ibid.), (5) exclamations (e.g., Oh God, exclamation marks), swear words (e.g., damn), colloquialism (e.g., buddy), words charged with strong emotions (e.g., bloody) (Leech \& Short, 2007). To identify an instance of FIT, (1) is obligatory, and (2), (3), (4) and (5) are optional, with at least one of them being present. To some extent, the tagging of one thought instance as FIT or IT does not merely rely on whether it involves a construction of inversion or not. It is decided by features associated with DT instead.

The following analyses focus on two FIT extracts as are identified abiding by the above standards. As FIT is likely to slip into other modes of thought presentation, the FIT extracts might occasionally include one or two instances of other thought presentation categories. For the ease of reference, sentences are divided according to the presence of full stops and are numbered sequentially starting from 1. Clauses separated by semicolons are numbered as 1.1, 1.2. Exclamations and questions constitute a sentence by themselves. The use of cohesive devices and cohesive chains is examined and their effects in the fiction are discussed.

\section{Results and Discussion}

\subsection{Extract 1: Mrs. Dalloway's Free Indirect Thought}

This extract presents the thoughts of Clarissa Dalloway, an upper-class woman and the heroine of the fiction who is on her way to buy flowers for her party and recollects one girlhood summer at Burton while walking through the bustling London neighborhood one morning in June.

For Lucy had her work cut out for her. (1) The doors would be taken off their hinges; (2.1) Rumpelmayer's men were coming. (2.2) And then, thought Clarissa Dalloway, what a morning - fresh as if issued to children on a beach. (3)

What a lark! (4) What a plunge! (5) For so it had always seemed to her, when, with a little squeak of the hinges, which she could hear now, she had burst open the French windows and plunged at Bourton into the open air. (6) How fresh, how calm, stiller than this of course, the air was in the early morning; (7.1) like the flap of a wave; (7.2) the kiss of a wave; (7.3) chill and sharp and yet (for a girl of eighteen as she then was) solemn, feeling as she did, standing there at the open window, that something awful was about to happen; (7.4) looking at the flowers, at the trees with the smoke winding off them and the rooks rising, falling; (7.5) standing and looking until Peter Walsh said, (7.6) "Musing among the vegetables?" (8) — was that it? (9) - "I prefer men to cauliflowers" (10) — was that it? (11) He must have said it at breakfast one morning when she had gone out on to the terrace-Peter Walsh. (12) He would be back from India one of these days, June or July, she forgot which, for his letters were awfully dull; (13.1) it was his sayings one remembered; (13.2) his eyes, his pocket-knife, his smile, his grumpiness and, when millions of things had utterly vanished (13.3) - how strange it was! (14)—a few sayings like this about cabbages. (15)

This extract consists of 15 sentences, with sentences 2, 7, and 13 further divided into clauses. Though reality is blended with memories, cohesive devices help to focus the reader's attention on some semantic concepts and offer clues to their interpretation of the character's thought processes. Basic elements in this extract are identified as follows: there are two characters, Mrs. Dalloway and Peter Walsh, one time period, in the morning, two places, garden and sea, and the major event is Mrs. Dalloway's recollection of Peter Walsh's words. Cohesive features in this extract are listed below.

Pronominal: one, which is usually used for generic reference and is taken to cover up for "we", designates a specific character, Mrs. Dalloway, and functions as a camouflage for her "I" as in "it was his sayings one remembered" (13.2), thus endowing her individual experience of remembering Peter's words with a general nature. $I t$, which often refers to a specific object, refers to an event. As shown below, the sentences that include "it" are listed in the left column, and the corresponding referents are listed in the right column. By using the highly abstract and somewhat emotionless "it", Mrs. Dalloway seems to suppress her otherwise sentimental feelings towards the past and therefore keeps the memories safely locked away without disturbing her life in reality.

[1] how strange it was! (14) it was his sayings one remembered (13.2)

[2] —was that it? (9) Musing among the vegetables? (8)

[3] —was that it? (11) I prefer men to cauliflowers. (10) 
Demonstrative: this and that are mostly used to suggest the physical distance of the head word in relation to the speaker. The two demonstratives, however, are employed in this extract to indicate the psychological distance of a particular situation in relation to the thinking character. It can be inferred from the context that this (7.1) makes exophoric reference to the morning where Mrs. Dalloway is situated here and now, i.e., the morning in "what a morning" (3), as is different from the morning in her memory; that $(9,11)$ refers downward to "his sayings" (13.2), and "a few sayings like this about cabbages" (15). As the choice of demonstratives suggests the emotional closeness Mrs. Dalloway feels towards the situations, despite the fact Mrs. Dalloway's thoughts largely focus on her past experience, the use of this for the current moment of thinking and that of that for the past memories implies her unconscious footing in reality.

Definite article: the definite article the often indicates that the event and the person are already known. "The door" (2.1) in its first appearance is already modified by a definite article. "[T]he hinges" (6) seem to refer upward to "their hinges" (2.1). A close contextual reading reveals that the former actually refers to the hinges of "door" (2.1) in reality and the latter refers to the hinges of "window" $(6,7.4)$ in her memory. As the door and the hinges are not previously mentioned, to some extent, they are known, and to Mrs. Dalloway alone, and the narrator pretends to recede into the background.

Meronym: vegetables (8), flowers (7.5), and trees (7.5) all describe part of garden in Mrs. Dalloway's memory, whereas beach (3) and wave $(7.2,7.3)$ that of her imaginary sea. Once the corresponding holonym is identified from the context, the setting which Mrs. Dalloway imagines herself in is clarified.

Hyponym: cauliflowers (10) and cabbages (15) each designate a particular type of vegetable (8). Mrs. Dalloway's uncertainty in naming the vegetable, along with the question "Was that it", reflects the inaccuracy of her memory and her attempt to rummage through her memory for the very name of the vegetable.

Repetition: The use of the same words with different references serves as an ingenious means to connect reality and memory. To be specific, the two hinges $(2.1,6)$ do not correspond to the same referent, with one being the hinge of the door and the other the hinge of the window. Likewise, Morning is used once and again, with morning (3) meaning the morning here and now and the following two instances of morning $(6,7.1)$ in the past. Another case in point is the repetition of the air $(6,7.1)$, which transits Mrs. Dalloway's thoughts from the current moment to the old times. Besides, the conversion of a verb into its corresponding noun form, a variant of repetition, helps to single out a particular action in reality and projects it into memory. The switch from "He said" to "his sayings" objectifies the action and stresses Mrs. Dalloway's obsession with Peter's speech.

In addition to the clarification of semantic concepts, references and lexical cohesive devices form cohesive chains, which are further interlocked. With regard to the settings, beach (3) in the present imagination and wave $(7.2,7.3)$ in the past imagination both belong to her fictitious "sea", and link Mrs. Dalloway's reality and recollection. As plunge, which usually co-occurs with "sea", is creatively associated with "the open air" (6), this suggests that Mrs. Dalloway compares her experience with the fresh air in the morning to that by the sea. Hence beach, wave, and plunge are connected on account of the sea image. Moreover, the "vegetable" chain can combine with flowers and trees, and form another setting chain, the "garden", which connects reality in Mrs. Dalloway's past and that in her present, and reminds Mrs. Dalloway of Peter's sayings. In short, Mrs. Dalloway is portrayed as passing from the morning in reality to the morning long ago, indulgent in the sea setting, with her memory evoked by the hinges and the vegetables, remembering Peter Walsh's words.

As can be seen from the above analyses, FIT has its internal connection underneath its apparent incoherence and disorganization. The disconnectedness is largely due to the abundant use of ellipsis and substitution in stream-of-consciousness fiction.

Ellipsis: the following omissions are indicated in parentheses. (Which/It was) fresh as if issued to children on a beach (3); (the air/it was) like the flap of a wave (7.2); (the air/it was like) the kiss of a wave (7.3); (the air/it was) chill and sharp (7.4); (one remembered) a few sayings like this about cabbages (15).

Substitution: so (6) is used to replace a succession of exclamations like "what a morning", "what a lark", and "what a plunge".

These two devices are employed to better imitate the fluidity of thought activity and emphasize the observations and impressions that successively come to Mrs. Dalloway. In addition to the omission of "the air" as in "like the flap of a wave" (7.2), "like" is also omitted in "the kiss of a wave" (7.3). The retention of "a wave" helps build parallel structures with the preceding text and create a smooth progression of thoughts. "[A] few sayings like this about cabbages" (15), which omits "one remembered", rephrases "his sayings" (13.2), and constitutes drastic contrast with "millions of things" (13.3), thus emphasizing the deep impression Peter's sayings have made on 
Mrs. Dalloway. "[S]o", which replaces "what a morning", "what a lark", and "what a plunge", links Mrs. Dalloway's real life and her memory, and therefore switches the scene from her trip to the florist to the one where she conversed with Peter Walsh.

\subsection{Extract 2: Septimus's Free Indirect Thought}

This extract depicts the thoughts of Septimus Smith, a shell-shocked veteran who hears a car backfire and mistakenly thinks himself responsible for the traffic congestion.

And there the motor car stood, with drawn blinds, and upon them a curious pattern like a tree, Septimus thought, and this gradual drawing together of everything to one centre before his eyes, as if some horror had come almost to the surface and was about to burst into flames, terrified him. (1) The world wavered and quivered and threatened to burst into flames. (2) It is I who am blocking the way, he thought. (3) Was he not being looked at and pointed at; (4.1) was he not weighted there, rooted to the pavement, for a purpose? (4.2) But for what purpose? (5)

This extract comprises 5 sentences, with sentence 4 divided into 2 clauses. Like Extract 1, this extract depicts the character's imagination as is incurred by reality. To be specific, it is about Septimus's imagination and meditation at the sight of the Queen's car. Here, references and lexical devices are again employed to stress some key semantic concepts.

In terms of pronouns, he (4.1, 4.2), his (1), him (1) and I (3) all refer to Septimus. As to synonyms, everything (1) and the world (2) describe the surrounding environment; terrify (1) and threaten (2) are used to depict Septimus's relations with the surrounding environment, i.e., the surrounding environment poses danger to his life. [W]ay (3) and its subordinate pavement (4.2) denote Septimus's actual situation. "burst into flames" $(1,2)$ and "purpose" $(4.2,5)$ are both repeated to indicate his imagination and meditation as is triggered by his experience in actuality. Besides, repetition functions as the bridge that links reality and imagination as in Extact 1. [D] rawn (1) and drawing (1) are different forms of the same lemma, with the former referring to the drawing of the blinds in reality, and the latter the drawing of everything in imagination, thus facilitating the transition from reality to imagination.

These cohesive devices can also be grouped into some major cohesive chains: one pronoun chain which concentrates on Septimus, four noun chains, horror, tree, everything/the world, and way, four verb chains, terrify/threaten, draw, burst, and root, and one preposition chain, for a/what purpose. To start with, horror associates with terrify/threaten and the two chains are therefore combined into one. Then, everything collocates with burst, and the two chains are also combined, which is further related with the "horror" chain, thus conveying the message that the burning world stands for the impending threat to Septimus, object of the verb terrify. Moreover, as root, which usually collates with tree, collocates with he here, it can be inferred that Septimus compares himself to a tree. The "he" chain is thus related to the drawing of everything by virtue of the drawn blinds with the image of a tree. The "way" chain and the "he" chain are further connected in the sense that Septimus envisages himself being rooted to the pavement and obstructing the traffic, which explains why he is terrified by the burning of the world. This raises the irreconcilable conflict between him and the world outside, and directs his attention to the fundamental question, "for what purpose" he lives, which is repeated and emphasized.

\subsection{Organic Relations}

Apart from cohesion of componential relations, the two extracts also use cohesive devices to build organic relations. Whereas the two members of the cohesive tie "form part of some message" (Halliday \& Hasan, 1985, p. 81) in componential relations, in organic relations, the members of the tie are "whole message(s) rather than message components" (ibid.). Conjunctives, in particular, can function as clues to sustain continuity of viewpoint (Ehrlich, 1990) or shift perspective (Sotirova, 2004) across sentences in the case of FIT. As in the following FIT examples [4] and [5], Mrs. Ramsay's exclamations and Septimus's second interrogation defy easy identification in terms of thought presentation category for lack of temporal and pronominal markers, and the use of conjunctives not only aids textural cohesion but also viewpoint consistency. To be specific, "for", which usually signals causal tie, indicates "a pseudo-logical sequence in a character's flow of thoughts" (Ikeo, 2015, p. 371). The perspective reflected in the sentence introduced by "for" is thus identified as the same as the preceding exclamations, namely, Mrs. Dalloway's perspective, and her thoughts seamlessly shift from this morning in London to one morning at Bourton years ago. Similarly, the adversative conjunction "but" in [5], along with the repetition of the prepositional expression "for what purpose", helps interpret "But for what purpose" as part of Septimus's thoughts, which are carried over from the preceding interrogation, and the war veteran is presented as continuously plagued by the quest for the meaning of life. 
[4] What a lark! What a plunge! For so it had always seemed to her, when, with a little squeak of the hinges, which she could hear now, she had burst open the French windows and plunged at Bourton into the open air.

[5] Was he not being looked at and pointed at; was he not weighted there, rooted to the pavement, for a purpose? But for what purpose?

However, there are more cases where connections are established without any salient cohesive devices. Zhang \& Liu (2003) argue that in such cases readers will be able to fill these gaps if the story is narrated in a certain order. To be specific, "in the text the sequences appear as a flow of information that either moves straightforward or in other manners; beyond the text, they represent the order in the physical world or that of men's mental activities (p. 183). Similarly, Woolf (2002 [1925]) advances the idea that novelists should convey the inner reality, i.e. the "varying", "unknown" and "uncircumscribed spirit, with as little mixture of the alien and external as possible" (p. 61) Thus, FIT follows more of the order in which the psychological sequence incurred by events in the physical world rather than the surface connections embodied in the cohesive relations.

\subsection{Theoretical Discussions}

By applying the cohesive devices to Mrs. Dalloway, I find that FIT stretches often resort to references and lexical cohesive devices to provide the most obvious way of "the relationship between two components in the text that can be explained with each other" (Hu et al., 2008, p. 179), that is, the formation of sense relations between language components, emphasizing semantic concepts like characters, events and the settings. Here references generally include pronouns, demonstratives and definite articles, and lexical devices include repetition, synonym and antonym, hypernym and hyponym, holonym and meronym. In FIT these devices are not self-evident and demand meticulous examination. Take the relations of co-referentiality as an example. Some expressions seem to signify the same referent while actually they do not, and some referents defy quick identification. There are also cases where some of the cohesive chains are missing, which need restoration. Thus one has to discern through the context and even assumed context the components that establish specific sense relations.

Besides, ellipses and substitutions are likely to be found in FIT in an attempt to avoid known or secondary information, and emphasize new or important information in a most succinct manner, and much effort is required to determine the omitted and substituted information through the context and pinpoint the new and important information as intended by the author. Moreover, conjunctives not only establish cohesive relations within FIT but also between FIT and narration, thus contributing to the blurred boundary between external reality and subjective thinking. But there are circumstances under which not a single conjunctive is found between and within clauses and the reader is compelled to follow the character's psychological order as is distinctive to stream-of-consciousness fiction to establish textual coherence.

\section{Conclusion}

Free indirect thought, is often considered a literary device or a type of content associated with stream of consciousness fiction, and its purposes "prominently include automatic gear shifting between narration and characters' minds, usually in the interests of empathy and narratorial inconspicuousness" (Fludernik, 1993, p. 70). With reality intertwined with imaginations and memories, the reader is likely to feel frustrated on processing the apparently illogical and incoherent text. Analyzing non-structural cohesive features of FIT extracts greatly facilitates the understanding and appreciation of the characters' psychological activities and their personality traits.

To begin with, references and lexical devices are important cohesive devices in FIT extracts and help to clarify significant threads in the character's thought processes. Mrs. Dalloway's free association between the morning air and the sea is ingenuously signaled by the node word plunge. In the same vein, Septimus's fanatic comparison between himself and a tree is indicated by root.

Next, cohesive devices are creatively employed in FIT extracts. For pronouns, the indefinite pronoun one is not used in its generic sense and refers to a specific thinking character, as in "it was his sayings one remembered", where one refers to Mrs. Dalloway instead of everyone, and personal experience is thus made universal.

With regard to synonyms, different lexical items with similar meanings are used to describe the inexactitude of memory and the processes involved in character's attempt to modify her expressions such as cauliflower and cabbage, or suggest recurring thoughts that haunt the character like terrify and threaten.

Apart from deepening the impression like fresh in Extract 1 and purpose in Extract 2, vocabulary repetition is used to achieve two special effects. For one thing, two words that are the same in form and part of speech can correspond to different referents and direct the reader's consciousness from reality to memories (e.g., hinge in Extract 1) or imaginations (draw in Extract 2). For another, two words with different forms or parts of speech as 
in the change from the verb say to its corresponding noun form saying in Extract 1 naturally connects Mrs. Dalloway's recollection of Peter's words and her observation on these words.

As to hypernyms and hyponyms, holonyms and meronyms, the two words thus linked are not necessarily found in the same text. Hyperhyms and holonyms, usually buried deep in the character's consciousness, are not verbalized. Positioning the sea image in Mrs. Dalloway's sub-consciousness, for instance, as the superordinate for beach and wave explicitly mentioned in the text, reinforces the authenticity and secrecy of her thoughts.

Substitutions and ellipses, that is, selectively omitting old information or structuring the same information in a different way, help create the smooth flow of thoughts and render new information conspicuous. The resultant disconnectedness may also be due to the fact that some thoughts are not clearly expressed in words, which requires the reader's efforts to fill the gaps from the context clues.

Finally, a similar set of cohesive devices have the potential to create different types of characters. For instance, the avoidance of substitution and ellipsis in Septimus's FIT extract indicates his numb feelings and preoccupations with rational reasoning. By contrast, more instances of substitution and ellipsis are found in Mrs. Dalloway's FIT extract, and she is depicted as sensitive and susceptible to external factors, constantly switching between her mental life and the world outside.

To sum up, exploring the non-structural cohesive features of FIT in stream-of-consciousness fiction reveals that the essential means to establishing coherence in narratives of this kind is to discern and follow the specific cohesive chains and the way these chains are further interlocked. In addition, examining FIT's internal connection proves an effective way to sort out the multitudinous thoughts passing through the character's mind and piece together the character's personality developing with the unfolding of the narrative. Further research is needed to confirm and generalize these findings concerning the use and effect of cohesion in fiction.

\section{References}

Auerbach, E. (2003[1953]). Mimesis: The Representation of Reality in Western Literature (Trans. W. Trask). Princeton, NJ: Princeton University Press.

Balossi, G. (2014). A Corpus Linguistic Approach to Literary Language and Characterization: Virginia Woolf's The Waves. Amsterdam/Philadelphia: John Benjamins Publishing Co. https://doi.org/10.1075/lal.18

Banfield, A. (1982). Unspeakable Sentences: Narration and Representation in the Language of Fiction. London: Routledge.

Chatman, S. (1978). Story and Discourse: Narrative Structure in Fiction and Film. Ithaca: Cornell University Press.

Cui, Y. (2014). Parentheticals and the presentation of multipersonal consciousness: A stylistic analysis of Mrs. Dalloway. Language and Literature, 23(2), 175-187. https://doi.org/10.1177/0963947014528112

Dick, S. (2001). Literary realism in Mrs. Dalloway, To the Lighthouse, Orlando and the Waves. In S. Roe \& S. Sellers (Eds.), The Cambridge Companion to Virginia Woolf (pp. 50-71). Shanghai: Shanghai Foreign Language Education Press.

Ehrlich, S. (1990). Point of View: A Linguistic Analysis of Literary Style. London: Routledge.

Fludernik, M. (1993). The Fictions of Language and the Languages of Fiction: The Linguistic Representation of Speech and Consciousness. London: Routledge.

Gavins, J., \& Steen, G. (Eds.) (2003). Cognitive Poetics in Practice. London: Routledge. https://doi.org/10.4324/9780203417737

Halliday, M. A. K., \& Hasan, R. (1976). Cohesion in English. London: Longman.

Halliday, M. A. K., \& Hasan, R. (1985). Language, Context and Text: Aspects of Language in a Social- Semiotic Perspective. Deakin: Deakin University Press.

Herman, D. (Ed.) (2011). The Emergence of Mind. Lincoln: University of Nebraska Press.

Hernadi, P. (1972). Dual perspective: Free indirect discourse and related techniques. Comparative Literature, 24, 32-43. https://doi.org/10.2307/1769380

Hu, Z., Zhu, Y., Zhang, D., \& Li, Z. (2008). Introduction to Systemic Functional Linguistics. Peking: Peking University Press.

Ikeo, R. (2015). Speech and thought presentation. In V. Sotirova (Ed.), The Bloomsbury Companion to Stylistics (pp. 356-379). London: Bloomsbury. 
Lambert, D. (2011). The Shifting Points of View in Virginia Woolf's Novel Mrs. Dalloway: Rooms, Corridors, and Houses. Lewiston, NY: Edwin Mellen Press.

Lee, H. (2010[1977]). The Novels of Virginia Woolf. London: Methuen.

Leech, G., \& Short, M. (1981). Style in Fiction: A Linguistic Introduction to English Fictional Prose. London: Longman.

Leech, G., \& Short, M. (2007). Style in Fiction: A Linguistic Introduction to English Fictional Prose (2nd ed.). London: Routledge.

McHale, B. (1978). Free indirect discourse: A survey of recent accounts. PTL: A Journal for Descriptive Poetics and Theory of Literature, 3, 249-278.

McHale, B. (2009). Speech representation. In P. Hühn, J. Pier, W. Schmid, \& J. Schönert (Eds.), Handbook of Narratology (pp. 434-446). Berlin \& New York: Walter de Gruyter.

Palmer, A. (2004). Fictional Minds. Lincoln: University of Nebraska Press.

Pascal, R. (1977). The Dual Voice: Free Indirect Speech and Its Functioning in the Nineteenth-century European Novel. Manchester: Manchester University Press.

Rundquist, E. (2014). How is Mrs Ramsay thinking? The semantic effects of consciousness presentation categories within free indirect style. Language and Literature, 23(2), 159-174. https://doi.org/10.1177/0963947014530771

Semino, E., \& Short, M. (2004). Corpus Stylistics: Speech, Writing, and Thought Presentation in an English Corpus of Writing. London: Routledge.

Shen, D. (1991). Reevaluation of the functions of free indirect speech. Foreign Language Teaching and Research Press, 2, 11-16.

Simpson, P. (1993). Language, Ideology and Point of View. London: Routledge. https://doi.org/10.4324/9780203312612

Sotirova, V. (2004). Connectives in free indirect style: Continuity or shift? Language and Literature, 13(3), 216-234. https://doi.org/10.1177/0963947004044872

Sotirova, V. (2007). Woolf's experiments with consciousness in fiction. In M. Lambrou \& P. Stockwell (Eds.), Contemporary Stylistics (pp. 7-18). London: Continuum.

Sotirova, V. (2013). Consciousness in Modernist Fiction: A Stylistic Study. Basingstoke: Palgrave Macmillan. https://doi.org/10.1057/9781137307255

Toolan, M. (2008[1996]). Language in Literature: An Introduction to Stylistics. Beijing: Foreign Language Teaching and Research Press.

Woolf, V. (1925). Mrs. Dalloway. London: Harcourt, Brace \& World.

Woolf, V. (2002[1925]). The Common Reader. Boston: Mariner Books.

Zhang, D., \& Liu, R. (2003). The Development and Applications of Textual Coherence and Cohesion Theory. Shanghai: Shanghai Foreign Language Education Press.

Zunshine, L. (2003). Theory of mind and experimental representations of fictional consciousness. Narrative, 11(3), 270-291. https://doi.org/10.1353/nar.2003.0018

\section{Copyrights}

Copyright for this article is retained by the author(s), with first publication rights granted to the journal.

This is an open-access article distributed under the terms and conditions of the Creative Commons Attribution license (http://creativecommons.org/licenses/by/4.0/). 